\title{
PRODUTOR RURAL FAMILIAR: UM ESTUDO SOBRE A ADESÃO AOS CONTROLES DE CUSTOS NA CIDADE DE LONDRINA-PR
}

\author{
Kelli Juliane Favato ${ }^{1}$ \\ Daniel Ramos Nogueira ${ }^{2}$
}

\section{RESUMO}

A produção rural familiar representa aproximadamente $70 \%$ dos alimentos consumidos no Brasil, tendo relevância para a economia nacional. Pesquisas recentes apontam que uma pequena parcela dos produtores rurais utiliza controles de custos no processo de tomada de decisão, mesmo sendo esta uma ferramenta essencial para a gestão da propriedade. Assim, a presente pesquisa tem como objetivo investigar a adesão aos controles de custos por produtores familiares da cidade de Londrina-PR. Cabe ressaltar, que a região tem forte vínculo com o agronegócio e a sobrevivência deste tipo de produtor é importante para a sustentabilidade e economia regional. O levantamento de dados foi realizado por meio de formulários na feira do produtor rural, sendo este, um programa municipal de incentivo para os produtores rurais familiares. Resultados evidenciam que os produtores fazem controles de custos considerados básicos, no entanto, não os utilizam no processo de tomada de decisão e formação do preço de venda. Verificase que um pequeno número de produtores criou estratégias para diminuir os custos diante da atual retração econômica.

Palavras-chave: agronegócio, contabilidade de custos, custos, produtor rural familiar.

\section{RURAL FAMILY PRODUCER: A STUDY ON THE ACCEPTANCE OF COST CONTROLS IN THE CITY OF LONDRINA-PR}

\begin{abstract}
Rural family production is of great relevance to the national economy, accounting for approximately $70 \%$ of the food consumption in Brazil. Recent research indicates that a small portion of rural producers use cost controls in the decision-making process, even though this is an essential tool for the property management. Thus, the present research aims to investigate the acceptance of cost controls by rural family producers in the city of Londrina-PR. It should be noted that the region has a strong connection with agribusiness and the survival of this type of producer is important for the

1 Graduada em Ciências Contábeis (UEL). Mestranda em Ciências Contábeis (UEM). E-mail: kelli.favato@gmail.com.

${ }^{2}$ Graduado em Ciências Contábeis (UEL). Mestre em Contabilidade (UFPR). Doutor em Controladoria e Contabilidade (FEA-USP). Docente Adjunto do Curso de Ciências Contábeis da Universidade Estadual de Londrina (UEL). E-mail: danielrnog@hotmail.com.
\end{abstract}


regional sustainability and economy. Data was collected through forms at the rural producer fair, which is a municipal incentive program for rural family producers. The results show that the producers' cost controls are considered basic, however, they do not use them in the decision-making process and for the sales pricings. It is noted that that a small number of producers have created strategies to reduce costs because of the current economic recession.

Keywords: agribusiness, costs accounting, costs, rural family producer.

\section{INTRODUÇÃO}

No decorrer dos anos o segmento rural foi aprimorado com novas técnicas e tecnologias de mecanização, adubação e controle de pragas, aumentando dessa forma os recursos, como também, os custos para plantação e cultivo. Atualmente, a atividade é relevante para a economia nacional representando $23 \%$ do PIB brasileiro, no ano de 2014 (PORTAL PLANALTO, 2015). Salienta-se que parte dessa contribuição é oriunda da produção rural familiar, responsável por $70 \%$ dos alimentos consumidos no Brasil (PORTAL BRASIL, 2015).

Diante da relevância da agricultura familiar para o segmento rural, o governo tem promovido diversas políticas de desenvolvimento para este setor, incluindo créditos de financiamentos, tal como o Programa Nacional de Fortalecimento da Agricultura Familiar (PRONAF) e o Programa de Aquisição de Alimentos (PAA), sendo este um projeto de apoio para a comercialização dos alimentos cultivados. No entanto, 0 atual cenário econômico contempla instabilidades, gerando uma retração econômica, na qual até mesmo o setor Agropecuário que conseguiu em 2015 manter o seu PIB positivo, em 2016 arcou com taxas negativas de geração de riqueza, acompanhando a recessão nacional (IBGE, 2016).

Com este cenário negativo, há uma perspectiva de piora para a maioria dos setores da economia nacional, suscitando dos gestores um processo mais sistêmico de monitoramento dos custos e recursos da entidade, visando sua sobrevivência no mercado. Nota-se a necessidade de encontrar meios para diminuir o impacto negativo dos labirintos criados pela economia, principalmente para o pequeno produtor familiar, que tem menor domínio de tecnologia e fontes para captação de recursos quando comparado a recursos de entidades maiores.

Conforme Santos, Marion e Segatti (2008, p. 23) "a agricultura será tão mais próspera quanto maior for o domínio que o homem venha a ter sobre o processo de produção, que se obterá na medida do conhecimento acerca das técnicas de execução e gerência". Neste contexto, a contabilidade de custos voltada para área do agronegócio exerce um papel relevante, como uma ferramenta para gerenciar e controlar as etapas de plantio, cultivo e comercialização dos produtos.

Ressalta-se, que a contabilidade de custos é pouco utilizada pelos produtores rurais para a tomada de decisões (ZANIN et al., 2014). Segundo Santos e Callado (2000) os gestores rurais têm conhecimento da Contabilidade Rural, mas ainda não têm compreensão da importância que a Contabilidade de Custos exerce para o controle e tomada de decisão no seu negócio.

Considerando a relevância do Produtor Rural Familiar e a Contabilidade de Custos aplicada a este segmento, a presente investigação é norteada pela seguinte questão de pesquisa: "Qual a adesão aos controles da contabilidade de custos por produtores rurais familiares da cidade de Londrina-PR?". Assim, o objetivo principal 
é investigar a adesão aos controles da contabilidade de custos por produtores rurais familiares da cidade de Londrina-PR.

A produção agrícola familiar tem relevância social e atualmente contempla grande visibilidade, tanto nacional, como também no âmbito internacional, de forma que governantes buscam incentivar e aprimorar o setor, por meio de programas de incentivos fiscais, financiamentos e negociações comerciais. Esta temática ainda é pouco explorada na literatura contábil, assim diante a esta lacuna de pesquisa e a importância social e econômica, a pesquisa justifica-se perante a necessidade de verificar a utilização da contabilidade de custos e controles de custos para a atividade da agricultura familiar.

O artigo é dividido em mais quatro seções além desta introdução, sendo que no próximo tópico será abordada a Revisão de Literatura sobre os conceitos utilizados. Em seguida, o capítulo de Aspectos Metodológicos detalhará o percorrer científico no processo de planejamento e coleta de dados. A Análise dos dados demonstrará os resultados e suas interpretações, e, por fim, as considerações finais apresentarão os achados da investigação, apontarão limitações e sugestões para futuras pesquisas.

\section{REVISÃO DA LITERATURA}

A revisão da literatura será estruturada em quatro tópicos, sendo eles: Agricultura Familiar, Contabilidade Aplicada ao Agronegócio, Gestão de Custos no Agronegócio e, por fim, Pesquisas Relacionadas.

\subsection{AGRICULTURA FAMILIAR}

No Brasil o modelo produtivo agropecuário adotado foi implantado na década de 1960, com uma ação conjunta do ensino, pesquisa e extensão (sindicatos, entre outros) (OLIVEIRA et al., 2017). Contudo, em meados de 1980 iniciou-se um processo de construção da categoria agricultura familiar, enquanto modelo de agricultura e como identidade política de grupos de agricultores. Esse processo decorre da, até então, invisibilidade socioeconômica e política da agricultura familiar (PICOLOTTO, 2014).

A agricultura familiar representa um conjunto de sistemas de produção que agregam diversas culturas e criação de animais, tanto para o consumo familiar quanto para o mercado (SANTOS; SIEBER; FALCÃO, 2014). O fator peculiar do setor está na sua composição, que engloba sujeitos, esses homens, mulheres, jovens e idosos que formam um grupo familiar que vive e trabalha na agricultura (PICOLOTTO, 2014).

Regulamentada pela Lei no 11.326 de julho de 2006, é definida por desenvolver atividades econômicas no meio rural, desde que a propriedade contemple os quatro requisitos básicos, sendo eles: deter até quatro módulos fiscais, predominar a mão de obra familiar, possuir percentual mínimo da renda familiar com origem nas atividades da propriedade e, a família deve gerir o negócio (BRASIL, 2006).

Para Guanziroli, Buainain e Di Sabbato (2012), pode-se observar subcategorias na literatura da agricultura familiar: (i) uma que possui tamanho suficiente para desenvolver uma agricultura moderna, empresarial, com escala de produção e, nesse sentido, pode se apropriar dos ganhos gerados pelas principais cadeias do agronegócio (complexo soja, fruticultura, lácteos etc.). Outra (ii) que se restringe a participar das cadeias de produtos alimentares, contribuindo também com o aumento na participação no Valor Bruto da Produção. E, (iii) o grupo de 
subsistência, mais parecidos com os camponeses do que com os anteriormente descritos.

Quanto ao terceiro grupo, a agricultura camponesa, Fernandes e Salamoni (2015) inferem que esta subcategoria agrega uma parcela significativa da população rural, do qual ultrapassa o paradoxo das imposições do sistema capitalista. Estabelecendo um "duplo processo de autonomia-subordinação camponesa, materializado em formas específicas de trabalhar a terra com os meios de produção disponíveis" (FERNANDES; SALAMONI, 2015, p. 165).

No cenário nacional, o governo tem promovido a criação de políticas estratégicas (como o PAA), para o fortalecimento desse setor, tais como: combate à pobreza rural, segurança e soberania alimentar, sustentabilidade dos sistemas de produção, sustentabilidade na geração de renda e agregação de valor. Com essas, - Estado pretende fortalecer a agricultura brasileira, através de estímulos, afim de incentivar a comercialização deste mercado (BRASIL, 2011).

No contexto internacional, governo e organizações estão voltados para o desenvolvimento da produção familiar no campo, de forma a desenvolver estratégias para o setor, com o intuito de proporcionar maior visibilidade do potencial que esses agricultores têm para erradicar a fome, preservar recursos do meio ambiente e ajudar para o desenvolvimento sustentável, assim, o ano de 2014 foi definido pela Organização das Nações Unidas (ONU, 2013) como o ano internacional da agricultura familiar.

Segundo Buainain e Silveira (2013, p. 2):

A preocupação legítima com a agricultura familiar tem custos e demanda investimentos públicos [...] em programas de capacitação em gestão da produção e de negócios (empreendedorismo no campo); no apoio às formas de organização que melhor aproveitam suas vantagens em explorar novos mercados de produtos e serviços, agrícolas e não agrícolas; e na provisão de recursos para formação de capacidade produtiva.

Diante do exposto, ressalta-se a importância de criar um paralelo entre o plantio e a capacidade técnica de gerir a produção, uma vez que, o desenvolvimento da agricultura familiar está ligado com o profundo conhecimento nos custos de produção e cultivo, visando assim manter a continuidade e prosperidade do negócio.

\subsection{CONTABILIDADE APLICADA AO AGRONEGÓCIO}

Marion (2012, p. 2) define que as "empresas rurais são aquelas que exploram a capacidade produtiva do solo por meio da terra, da criação de animais e da transformação de determinados produtos agrícolas". Ainda segundo o autor, "a contabilidade de ativos biológicos abrange tudo aquilo que nasce, cresce e morre, desde as culturas temporárias e permanente até os animais, rebanhos de reprodução e corte" (MARION, 2012, p. 33).

A contabilização dos ativos biológicos é normatizada pelo International Accounting Standards Board (IASB) no IAS 41 - Agriculture, no Brasil correlacionado com o CPC 29 - Ativo biológico e Produto Agrícola, emitido pelo Comitê de Pronunciamentos Contábeis (CPC, 2009). Essa norma estabelece as premissas para Reconhecimento, Mensuração e Evidenciação dos ativos biológicos nas demonstrações contábeis. 
A contabilidade é um recurso para controle que permite aos usuários acompanhar diretamente a produção da empresa. Sendo esse gerenciamento, principalmente quando aplicado a custos, essencial para acompanhar o avanço no que tange a produtividade rural (HALL et al., 2008).

Os controles contábeis estão diretamente relacionados ao agribusiness, na medida em que, abrangem aos meios de controle, apuração de custos, determinação de preço e fornecimento de informação para tomada de decisão, fortalecendo dessa forma, a cadeia agroindustrial (GRATERON, 1996).

Para Hofer et al. (2011, p. 32) a contabilidade rural "auxilia sobremaneira na geração de informações para o planejamento e o controle das atividades e, por consequência, na sua estrutura".

Para que a contabilidade possa expressar com relevância a informação contábil é necessário que o sistema de gestão de custos funcione adequadamente. Ciente dessa importância, apresenta-se no próximo tópico sobre a Gestão de Custos no Agronegócio.

\subsection{GESTÃO DE CUSTOS NO AGRONEGÓCIO}

A Contabilidade de Custos engloba todos os elementos gastos na produção, em aspecto de caracterização, seu principal intuito é a avaliação de estoques e mensuração do lucro. Dentre suas especificações, preocupa-se com os controles dos custos, sendo inclusive um dos seus objetivos comparar o planejado com o realizado. Seguindo a vertente, a Contabilidade de Custos é voltada para a tomada de decisão, da qual indagam respostas como quais produtos são os mais rentáveis, qual item é recomendado comprar de terceiros ou manter a produção própria, entre outros (SANTOS; MARION; SEGATTI, 2008).

Esta mesma contabilidade de custos que historicamente serve as atividades comerciais e industriais também pode ser aplicada as atividades rurais, contribuindo assim para que o produtor rural possa conhecer e controlar seus custos de produção.

Callado e Callado (1999, p. 1), no que se refere a custos rurais, defendem que "possuem características próprias, obedecendo a natureza da atividade econômica específica em exploração", com isso, não existe um procedimento padrão de aplicação da contabilidade de custos a todas as atividades agropecuárias, sendo que cada atividade pode ter demandas diferentes, como controles de custos de matéria-prima, insumos de produção e depreciações diferentes de acordo com o tipo de cultivo.

Para Marion (2012, p. 141) "conhecer o custo real de cada lote ou do rebanho a qualquer momento é uma informação imprescindível à gerência, não só para se apurar a rentabilidade após a venda, mas também (o que é mais importante) para determinar o ponto ótimo de venda". Controlar os custos durante o período de produção é importante, assim como também, vender no momento adequado, considerando as oscilações de preço do mercado, fatos estes que podem ser cruciais para uma rentabilidade satisfatória.

\subsection{PESQUISAS RELACIONADAS}

É notória a dimensão que o segmento rural proporciona para economia brasileira, pesquisas recentes abordam a importância da contabilidade para mensurar a riqueza natural no agronegócio, como também, um alicerce estratégico para identificar falhas no processo. 
Barbalho (2005) objetiva contribuir com a contabilidade rural (dando ênfase na pecuária), considerando que o uso adequado de dados contábeis propicia vantagens competitivas ao empreendedor. Na pesquisa, o autor procura demonstrar a importância da contabilidade e os subsídios que a mesma oferece por meio de seus relatórios. A metodologia aplicada foi a pesquisa de campo exploratória nos escritórios contábeis da cidade de Nova Andradina-MS, o que proporcionou verificar que os pecuaristas pouco utilizam as informações contábeis para a tomada de decisão e o papel dos escritórios contábeis tem sido apenas de um facilitador para diminuir o impacto tributário no negócio. O Autor ressalta a importância do contabilista e o gestor de aproximarem ideias, visto que a missão de ambos é a continuidade do empreendimento agropecuário.

Da mesma forma, pesquisando público relacionado com agronegócio na Espanha, Bosch, Aliberch e Blandón (2012, p. 127) encontraram que os "produtores rurais geralmente viam os procedimentos contábeis como desnecessários, e úteis somente para finalidades tributárias", tais quais os produtores brasileiros. Nota-se que a mensuração de custos da contabilidade rural permeia algumas limitações, devido ao fato da mesma estar associada apenas às suas finalidades fiscais.

Callado e Callado (2003) consideram que os custos devem ser desenvolvidos de forma específica para cada negócio. A pesquisa exploratória de custos no processo de tomada de decisão em empresas rurais foi realizada no estado do Ceará com agroindústrias processadoras de raspa de mandioca, através de questionários. Os autores coletaram informações quanto à avaliação de custos em diversos procedimentos, tais como: grau de ocupação da capacidade instalada, custos na determinação do preço de vendas, avaliação de matérias-primas, entre outros. A pesquisa permitiu aos autores evidenciar que os custos são utilizados como parâmetros para tomada de decisão, no entanto, o baixo nível de escolaridade e baixo conhecimento técnico, limitam o desenvolvimento de procedimentos mais completos e a consequência disto é falta precisão na apuração e no controle, o que compromete a qualidade da informação disponibilizada para o gestor agroindustrial.

Visando analisar a percepção dos gestores rurais, sobre a contabilidade como instrumento de apoio ao negócio, Kruger et al. (2014) identificaram as principais características do uso das técnicas contábeis em propriedades rurais. A pesquisa descritiva, por meio de um levantamento no Município de Erval GrandeRS, aplicada por questionários a produtores rurais, proporcionou verificar que existe uma baixa percepção pelos produtores quanto a importância contábil para suporte no processo de gestão de negócios.

O estado de Santa Catarina é referência por sua produtividade rural em determinados segmentos, o estudo realizado por Zanin et al. (2014) teve por objetivo identificar as fragilidades da estrutura e gestão das propriedades rurais do oeste de Santa Catarina. A metodologia utilizada foi a coleta dos dados, através da aplicação de questionários, com proprietários rurais dos municípios de Quilombo, Coronel Freitas e Cordilheira Alta. O resultado da pesquisa evidenciou a carência no uso de informações contábeis por produtores rurais, devido ao fato da maioria não utilizar os relatórios gerenciais para analisar custos do seu negócio. Os autores ressaltam que existe uma fragilidade para o processo de continuidade das propriedades rurais do oeste de Santa Catarina.

Walker (2014), em seu estudo "Drought, Resettlement and Accounting" (Seca, Restabelecimento e Contabilidade), abordou o desastre natural da seca que atingiu o território americano na década de 30 e tratou da importância contábil para a reestruturação dos produtores rurais. Diante da calamidade nacional, o governo criou projetos de reassentamentos para as famílias rurais afetadas, deslocando-as para terras mais produtivas e menos áridas. A pesquisa tem como base o Red River 
Valley Farms Project, instituído na Dakota do Norte, considerando que os registros de planejamento e orçamento das famílias eram obrigatórios, Walker (2014) considera que os registros contábeis dos produtores rurais contribuíram para o sucesso de realocação das famílias, de forma que o governo pôde monitorar o progresso nos novos estabelecimentos rurais como também identificar onde era necessária mais atenção. Segundo Walker (2014, p. 3), a contabilidade teve papel de "[...] uma chave tecnológica facilitadora na fase de recuperação de um desastre".

\section{ASPECTOS METODOLÓGICOS}

Com base na metodologia é possível ter maior confiabilidade das informações obtidas, e no decorrer desta fase, deverá ser definido critérios para elaboração do artigo, tais como onde, como e com quê (LAKATOS; MARCONI, 2003). Assim, por meio de um planejamento sistêmico a pesquisa terá alicerces conceituais para que alcance os objetivos propostos.

Quanto a classificação metodológica, pode-se classificar a pesquisa como Descritiva e Qualitativa. No que se refere ao método descritivo, Rampazzo (2002, p. 53) detalha que "a pesquisa descritiva observa, registra, analisa e correlaciona fatos ou fenômenos (variáveis), sem manipulá-los". O mesmo autor (2002, p. 53) considera que o método descritivo busca "[...] descobrir, com a precisão possível, a frequência com que um fenômeno ocorre, sua relação e sua conexão com outros, sua natureza e suas características".

Seguindo esta linha de raciocínio, o presente estudo busca verificar se os produtores familiares têm controles de custos e se os utilizam no processo de tomada de decisão.

O procedimento de coleta de dados inicialmente estabelecido foi o questionário e as questões utilizadas foram baseadas na literatura já existente (BARBALHO, 2005; KRUGER et al., 2014). Assim, objetivando adequar as questões de forma que o respondente tenha compreensão e clareza do que se indagava, optou-se por realizar um pré-teste com feirantes (produtores familiares) com as mesmas características da posterior amostra, porém de um município vizinho.

No pré-teste foi possível observar algumas dificuldades, tais como: o respondente relacionar o contexto da contabilidade de custos ao cotidiano da plantação, nesse ponto foi perceptível o pouco conhecimento com terminologias de gestão de negócio e a dificuldade de assimilar individualmente na leitura o contexto devido à baixa escolaridade.

Outro aspecto levantado no pré-teste está no produtor familiar manter atenção e concentração para responder, pois o questionário foi preenchido concomitantemente com o atendimento aos clientes na feira e realizar em outro período inviabilizaria a pesquisa diante a dificuldade de localizar esses produtores.

Mediante essas percepções no pré-teste, o questionário foi adaptado para formulário objetivando otimizar o procedimento de coleta de dados e adequar terminologias mais acessíveis para o produtor. As perguntas readequadas permaneceram com base nas pesquisas existentes (BARBALHO, 2005; KRUGER et al., 2014).

Após a definição do uso do formulário a coleta de dados foi realizada nas duas feiras que participam no Programa Municipal do Produtor Rural de LondrinaPR, enquadrado na Lei Federal do Produtor Rural Familiar. O local está situado em duas regiões, uma localizada na área central e a outra na zona norte da cidade. A coleta de dados ocorreu em três domingos entre os meses de Dezembro/2015 e Janeiro/2016, no período da manhã entre as 07:00 às 11:30 horas. 
Neste formato, no momento da coleta, o respondente não detinha em mãos o formulário, sendo perguntas e respostas procedidas através do diálogo. O formulário elaborado contemplava 21 questões fechadas objetivas (questões dicotômicas e múltipla escolha) e uma questão aberta, que possibilita ao respondente ter maior liberdade para expressar sua opinião. A técnica empregada propiciou extrair algumas perspectivas na fala do respondente.

A ordem do questionário foi estabelecida em quatro etapas: informações sobre o respondente; informações sobre a propriedade; gestão do negócio e, por fim, informações sobre a gestão de custos do negócio. Salienta-se a importância das duas primeiras etapas no processo de identificação dos requisitos para ser um produtor familiar rural. Por último, foi ofertado um curso de contabilidade de custos em parceria com a Universidade, visando retorno social da pesquisa.

A população selecionada abrange os produtores familiares cadastrados no programa feira do produtor da Prefeitura do Município de Londrina-PR. Programa este que é regulamentado pela Lei Municipal oㅜ 7.288, de 22 de dezembro de 1997. Para a escolha da amostra foi levado em consideração alguns pontos, sendo eles: cidade de grande influência para a sua região metropolitana, região possui forte vínculo com o cultivo agrícola e, o programa municipal da feira do produtor, considerando que neste são permitidos apenas produtores rurais cadastrados na prefeitura, regulamentados e que comercializem os produtos por meio da nota fiscal.

Quanto à abrangência, a população da pesquisa era de 47 produtores familiares e o número de respondentes foi de 22 produtores $(47 \%)$. O número de entrevistados menor que a população justifica-se devido ao fato de alguns produtores recusarem a responder e outros não estarem presentes nos dias em que foi realizada a coleta de dados.

Os dados coletados foram analisados utilizando-se de estatística descritiva com uso do Microsoft Excel ${ }^{\circledR}$.

\section{ANÁLISE DOS DADOS}

O presente tópico tem o intuito de demonstrar os resultados obtidos com a coleta de dados realizada junto aos produtores rurais familiares, de forma a agrupar e evidenciar características da população, partindo da aplicação do método descritivo.

\subsection{PERFIL DOS RESPONDENTES}

No que se refere ao perfil dos produtores foi possível aferir que $72 \%$ dos respondentes atuam no campo por mais de 20 anos, 50\% cursaram até o ensino fundamental e $50 \%$ o ensino médio, sendo que um deles cursou ensino (médio) técnico em contabilidade. A produção predominante é de Hortaliças e Verduras com $62 \%$ e as produções em escala secundária são de milho e feijão. Enquadra-se os respondentes, conforme tópico 2.1 proposto por Guanziroli, Buainain e Di Sabbato (2012) na subcategoria de produtor rural familiar do grupo de subsistência, próximos aos camponeses.

Ressalta-se que foram aplicadas quatro questões para averiguar se os produtores cadastrados no programa de produtor rural de Londrina estão enquadrados na Lei federal $\mathrm{n}^{0} \mathbf{1 1 . 3 2 6}$ de julho de 2006, do produtor familiar. Assim, foi investigado se as propriedades tinham até quatro módulos fiscais (que no município de Londrina representa limite de 48 hectares), se há predominância da mão de obra familiar, o percentual mínimo da renda familiar com origem nas atividades da propriedade e, por fim, se a família é quem dirige o negócio. Após 
analisadas as respostas pode-se inferir que todos os pesquisados estavam de acordo com as normas estabelecidas pela referida lei.

\subsection{CONTROLES DE CUSTO}

A primeira questão tinha o objetivo de verificar se os feirantes possuíam conhecimento dos custos no cultivo de cada espécie da propriedade. Conforme pode-se verificar (Tabela 1) a maioria dos respondentes confirmaram conhecer os custos de cada espécie. Salienta-se a importância em conhecer o real custo de cada elemento que compõe a produção total da propriedade, uma vez que esta informação estabelece diretrizes para formação de preço, entre outras variáveis.

Tabela 1 - Custo de cada espécie

\begin{tabular}{ccc}
\hline Conhecimento & Frequência & $\%$ \\
\hline Sim & 17 & 77 \\
Não & 5 & 23 \\
Total & $\mathbf{2 2}$ & $\mathbf{1 0 0}$ \\
\hline
\end{tabular}

Fonte: Dados da pesquisa.

Ato contínuo, questionou-se a existência de algum tipo de controle sistematizado destes custos. Com os dados da Tabela 2 é possível evidenciar que as respostas se mantiveram em percentuais constantes com a Tabela 1. Contudo, 2 dos 17 produtores que declararam possuir conhecimento no custo de cultivo, não possuem nenhum controle dos custos mensais. Ao mesmo passo que, 2 dos 5 produtores, que na tabela anterior declararam não conhecer os custos, possuem anotações de controle em cadernos.

Durante a coleta de dados dialogada com base no formulário foi possível inferir que o produtor rural familiar relata ter conhecimento nos custos de plantação devido a sua experiência no campo. Algumas falas corroboram nesse sentido, devido a atividade ser praticada hereditariamente e, a plantação e cultivo serem cíclicos, aliados ao fato das pequenas propriedades não terem métodos de mecanização modernos, logo não há grande variação além da econômica.

Tabela 2 - Controles de custos

\begin{tabular}{lcc}
\hline Métodos & Frequência & $\%$ \\
\hline Desconhece & 5 & 23 \\
Anota em caderno & 17 & 77 \\
Contador entrega o controle & - & - \\
Planilha de Excel & - & - \\
Sistema informatizado & - & - \\
Total & $\mathbf{2 2}$ & $\mathbf{1 0 0}$ \\
\hline \multicolumn{2}{c}{ Fonte: Dados da pesquisa. }
\end{tabular}

Analisando a Tabela 3, pode-se verificar que a maioria (54\%) dos produtores comercializa as mercadorias de acordo com os preços definidos com base na margem de lucro esperada, diante disso, ressalta-se a importância em manter os controles de custos atualizados, com dados confiáveis para ter informação suficiente para formulação do preço de venda.

No entanto, verifica-se como expressivo (46\%) o percentual de produtores que definem o preço de venda de acordo com o mercado, nesse caso em específico o conceito de mercado para esse público alvo são os comércios de lojas, mercados, supermercados e hipermercados da cidade. Assim, é importante destacar que há um risco de os preços destes estabelecimentos (supermercados etc.) serem inferiores 
ao valor necessário para se obter lucro com a produtividade, reforçando assim a necessidade premente de um controle de custos apurado.

Vale ressaltar a particularidade da atividade quando a comercialização é realizada nas feiras, tendo em vista um fator cultural do consumidor solicitar descontos diretos no produto ou comprar um alimento e ganhar outro de brinde. Essas estratégias foram relatadas como uma forma de competir com os mercados e manter um preço atrativo. Além dessa estratégia, foi apontado a competitividade na própria feira, no qual os produtores relataram manter um preço próximo entre as bancas que trabalham com a mesma qualidade de produto.

Tabela 3 - Definição do preço de venda

\begin{tabular}{lcc}
\hline Métodos & Frequência & $\%$ \\
\hline Oferecido por cooperativas & - & - \\
Informado por sindicatos & - & - \\
Oferecido pelo mercado & 10 & 46 \\
Definido pelo produtor & 12 & 54 \\
Total & $\mathbf{2 2}$ & $\mathbf{1 0 0}$ \\
\hline
\end{tabular}

Fonte: Dados da pesquisa.

A Tabela 4 evidencia que os produtores não detêm conhecimento em contabilidade de custos (54\%). Contudo, há um pequeno percentual de produtores que possuem conhecimento suficiente ou razoável. Os dois produtores que assinalaram possuir conhecimento razoável em contabilidade de custos utilizam esses conhecimentos frequentemente nas decisões sobre cultivo e venda de produtos da propriedade.

O produtor que analisou ter conhecimento suficiente, autodeclara utilizar os dados das suas anotações em cadernos e seus conhecimentos de contabilidade de custos em todas as análises pertinentes as decisões do negócio. Este último, tem formação de técnico contábil, permitindo assimilar a importância do conhecimento técnico para as tomadas de decisões.

Tabela 4 - Conhecimento em contabilidade de custos

\begin{tabular}{lcc}
\hline \multicolumn{1}{c}{ Nível } & Frequência & $\%$ \\
\hline Nenhum & 12 & 54 \\
Insuficiente & 7 & 31 \\
Razoável & 2 & 8 \\
Suficiente & 1 & 5 \\
\multicolumn{1}{c}{ Total } & $\mathbf{2 2}$ & $\mathbf{1 0 0}$ \\
\hline & Fonte: Dados da pesquisa.
\end{tabular}

Cientes do baixo nível de conhecimento de Contabilidade de Custos (Tabela 4), mas que havia algum tipo de controle dos custos em cadernos (Tabela 2), questionou-se sobre como é o processo de tomada de decisão dos produtores familiares (Tabela 5). Apenas 31\% toma decisão utilizando as anotações realizadas nos cadernos. Os resultados indicam que em grande parte o processo decisorial é guiado pelo conhecimento adquirido no decorrer dos anos atuando na atividade. Para Fernandes e Salamoni (2015), o fator hereditário marca um fator expressivo da família camponesa, que é o coletivismo interno de tomar as decisões diante eventos já vividos com base na experiência. 
Tabela 5 - Tomada de decisões

\begin{tabular}{l|c|c}
\hline Bases & Frequência & $\%$ \\
\hline Conhecimento do produtor & 15 & 69 \\
Demonstrações contábeis & - & - \\
Anotações feitas pelos próprios empresários & 7 & 31 \\
\hline Total & $\mathbf{2 2}$ & $\mathbf{1 0 0}$ \\
\hline
\end{tabular}

Fonte: Dados da pesquisa.

Em complemento, a coleta de dados permitiu inferir que 54\% dos entrevistados separam as despesas de casa das despesas com o cultivo, contra $46 \%$ dos produtores que não separam as despesas. Salienta-se a importância desta separação, para que o produtor saiba exatamente qual a lucratividade da atividade.

Pode-se perceber também que dos entrevistados, $70 \%$ não realizam contabilidade, referente ao restante da amostra $15 \%$ da contabilidade é realizada em escritórios e $15 \%$ por contador autônomo. Os 30\% que realizam contabilidade (com escritório ou contador autônomo), acreditam que a mesma tem a finalidade apenas de prestar contas ao fisco. Resultados estes semelhantes aos obtidos em outra pesquisa no Brasil (BARBALHO, 2005) e no Exterior (BOSCH; ALIBERCH; BLANDÓN, 2012).

Ainda com a coleta de dados verificou-se que $62 \%$ dos produtores rurais familiares cadastrados na feira do produtor de Londrina-PR, estão satisfeitos com o negócio e a rentabilidade no mercado, $15 \%$ representam o número de insatisfeitos e $23 \%$ consideram-se nem satisfeitos e nem insatisfeitos com a produção no campo.

Destaca-se que $15 \%$ dos entrevistados participaram de cursos/treinamentos para aperfeiçoamento no campo, e, do total de entrevistados, nenhum realizou treinamentos ou cursos na área de gestão de negócios. Também não houve adeptos ao curso ofertado pelos pesquisadores em parceria com a Universidade, isso devido ao fato de alegarem que não é viável ir até o campus Universitário.

Posição esta que corrobora com o estudo realizado na região de LondrinaPR de Oliveira et al. (2017), pois os autores inferem que a relação entre a academia e os produtores familiares deve ser prioritária e permanente, pois o desenvolvimento da agricultura familiar vai de encontro aos interesses de setores do agronegócio como um todo.

Quando questionados se diante da elevação de preços de materiais como energia elétrica, água, insumos, entre outros, houve alguma medida para conter os custos de produção, $30 \%$ responderam que sim, sendo que a principal iniciativa foi a contenção nos gastos com água.

Cabe mencionar, após a análise dos dados, que há semelhanças nos resultados que esta pesquisa abrange, com pesquisas anteriores realizadas em outras regiões do País, tais como, a dissertação realizada por Barbalho (2005) em Nova Andradina-MS, centro-oeste brasileiro, que destaca como pequena a representatividade de pecuaristas que utilizam as informações contábeis para a tomada de decisão.

Partindo para a pesquisa de Callado e Callado (2003), no Ceará (nordeste brasileiro), reconhece a utilização de custos como meio de tomada de decisão, no entanto, faz um paralelo com o nível de escolaridade e baixo conhecimento técnico para apuração destes que geram falta de precisão para apuração. Essa semelhança pode ser evidenciada na presente pesquisa, devido nenhum dos produtores terem cursos para capacitação de gestão.

Ainda referente à semelhança entre regiões, a pesquisa de Kruger et al. (2014) realizada no estado do Rio Grande do Sul, destaca a baixa percepção em relação à contabilidade para auxílio na gestão do negócio. Zanin et al. (2014), 
permanecendo na região sul brasileira, no estado de Santa Catarina, ressaltam que a maioria dos produtores não utilizam relatórios para analisar os custos dos negócios.

\section{CONSIDERAÇÕES FINAIS}

O objetivo principal proposto nesta pesquisa foi de investigar a adesão aos controles de custos por produtores familiares da cidade de Londrina-PR. Com a análise dos formulários aplicados é possível evidenciar que a maioria possui controles por meio de anotações em cadernos, porém pouco se utiliza as anotações para tomadas de decisões no cultivo e comercialização dos alimentos. Pode-se complementar que a utilização dos recursos de custo é considerada básica, não havendo uma separação mais detalhada ou relatórios mais apurados da lucratividade por produto ou linha de produção.

Diante dos resultados analisados é possível concluir, que existe uma fragilidade no que tange os controles e principalmente no uso de ferramentas de custos, considerando que a maioria dos entrevistados faz anotações, porém estas são simples, quando comparada com as usuais na contabilidade. Além disso, os produtores não as levam em consideração para a tomada de decisão, sendo que estas poderiam auxiliar nas contenções e reduções de gastos perante a atual retração no mercado. Ainda que a característica dos respondentes seja a atividade rural voltada as estruturas camponesas, os controles de sua atividade podem melhorar a sua produtividade.

Um fator importante resultante da pesquisa é aferir o pequeno número de feirantes que realizaram cursos para melhoria da produção (conforme destacado no capítulo anterior, apenas $15 \%$ participou de cursos/treinamentos), o município fornece o curso de manipulação de alimentos para produtores que plantam determinados espécies, no entanto, durante a aplicação dos questionários houve críticas quanto à metodologia do curso. Outro fator relevante, ainda na temática de cursos, é poder constatar que nenhum dos produtores realizou cursos de gestão ou custos dos negócios, alegando que aprenderam a gestão com antecessores.

A revisão de literatura estendeu-se a diversas regiões, constatando-se que é uma praxe dos produtores rurais, familiares ou não, não utilizar controles de custos para o plantio, colheita e comercialização, enfraquecendo assim, o conhecimento do próprio negócio. Ressalta-se que o controle de custos é uma das ferramentas pouco utilizada pelos empreendedores rurais, porém, cabe uma conscientização de que com os custos evidenciados é possível fornecer informações que serão base na tomada de decisões no decorrer do cultivo, assim como também, de determinar o melhor preço para comercialização.

Com o intuito de retribuir o tempo disponibilizado pelos respondentes e considerando o papel de formador social de uma Universidade, foi proposta a realização de um curso de controle de custos para os produtores familiares, no entanto, os produtores alegaram não ter tempo hábil para se deslocarem da propriedade para a Universidade. Dessa forma, optou-se por elaborar uma cartilha didática com conceitos de contabilidade de custos aplicadas especificamente ao cultivo e comercialização de alimentos, sendo disponibilizada à Secretaria de Agricultura de Londrina-PR para distribuição na feira do Produtor Rural.

Como já exposto, o segmento rural familiar é relevante para o PIB nacional e a resposta do Governo para os produtores é positiva, na medida em que estão abrindo caminhos com incentivos à produção. Contudo nessa pesquisa, notou-se uma fragilidade de gestão sistêmica para o produtor familiar, ao mesmo tempo entende-se as limitações tecnológicas do campo, assim o sistêmico aqui referido é 
para controles históricos ainda que manuais. Entende-se como responsabilidade dos produtores rurais terem maior conhecimento dessas medidas para utilizá-las no campo, ao mesmo passo, que compete aos órgãos públicos informarem de forma transparente tais medidas à população.

Sugere-se aos órgãos públicos locais que proporcionem maior incentivo aos produtores, no que se refere às temáticas de gestão do negócio, controle de custos, contabilidade gerencial, visto que as mesmas são importantes para o resultado final.

Os resultados da pesquisa devem ser analisados considerando algumas limitações, tais como, número de respondentes reduzido e em apenas um município.

Sabendo da vasta extensão territorial agrícola e a relevância do produtor rural familiar, espera-se que a temática possa ser investigada em futuros trabalhos, abrangendo um número maior na amostra, assim como também, outros programas de incentivo do Governo para o produtor rural familiar. Além disso, sugere-se comparação com os produtores familiares de outros países, visto que em outros continentes os produtores familiares também apresentam relevância social e econômica (YE; PAN, 2016).

\section{REFERÊNCIAS}

BARBALHO, V. F. A utilização das informações contábeis na tomada de decisão pelos gestores do negócio pecuária bovina de corte, na região de Nova Andradina, MS. 2005. 156 f. Dissertação (Mestrado em Controladoria e Contabilidade Estratégica) - Centro Universitário Álvares Penteado, São Paulo-SP, 2005.

BOSCH, J. M. A.; ALIBERCH, A. S.; BLANDÓN, J. G. A comparative study of difficulties in accounting preparation and judgement in agriculture using fair value and historical cost for biological assets valuation. Revista de Contabilidad, v. 15, n. 1, p. 109-142, 2012.

BRASIL. Lei oㅜ 11.326, de 24 de julho de 2006. Estabelece as diretrizes para a formulação da política nacional da agricultura familiar e empreendimentos familiares rurais. Brasília, 2006. Disponível em: <http://www.planalto.gov.br/ccivil_03/_ato20042006/2006/lei/l11326.htm>. Acesso em: 30 ago. 2015.

BRASIL. Lei no 12.512, de 14 de outubro de 2011. institui o programa de apoio à conservação ambiental e o programa de fomento às atividades produtivas rurais; altera as Leis n. 10.696, de 2 de julho de 2003, 10.836, de 9 de janeiro de 2004, e 11.326, de 24 de julho de 2006. Brasília, 2011. Disponível em: <http://www.planalto.gov.br/ccivil_03/_Ato2011-2014/2011/Lei/L12512.htm\#art33>. Acesso em: 03 dez. 2016.

BUAINAIN, A. M.; SILVEIRA, J. M. Agricultura familiar e tecnologia no Brasil. Jornal da Unicamp, Campinas, Ano XVII, no 217, Junho/2013. Disponível em: $<$ http://www.unicamp.br/unicamp/unicamp_hoje/jornalPDF/217pag02.pdf >. Acesso em: 30 Ago. 2015.

CALLADO, A. A. C.; CALLADO, A. L. C. Custos: Um desafio para a gestão no Agronegócio. In: Congresso Brasileiro de Custos, VI, 1999, São Paulo. Anais... São Paulo: ABCustos, 1999. p. 1-12. 
CALLADO, A. A. C.; CALLADO, A. L. C. Custos no processo de tomada de decisão em empresas rurais. Contabilidade, Gestão e Governança, v. 6, n. 1, p. 55-77, 2003.

CERVO, A.; BERVIAN, P. Metodologia científica. 4. ed. São Paulo: Makron Books, 1996.

COMITÊ DE PRONUNCIAMENTOS CONTÁBEIS (CPC). Pronunciamento CPC 29: ativo biológico e produto agrícola. 2009. Disponível em: <http://static.cpc.mediagroup.com.br/Documentos/324_CPC_29_rev\%2008.pdf>. Acesso em: 05 Ago. 2017.

FERNANDES, S.; SALAMONI, G. C. O Sistema da Agricultura Familiar Camponesa: Um Estudo no Distrito de Santa Teresinha, Palmeira das Missões. Sociedade e Território, v. 27, p. 149-167, 2015.

GRATERON, I. R. G. Contabilidade de animais difíceis de ser inventariados. In: MARION, J.C. (Org.). Contabilidade e Controladoria em Agribusiness. 5. ed. São Paulo: Atlas, 1996.

GUANZIROLI, C. E.; BUAINAIN, A. M.; DI SABBATO, A. Dez anos de evolução da agricultura familiar no Brasil: (1996 e 2006). Revista de Economia e Sociologia Rural, Brasília, v. 50, n. 2, p. 351-370, jun. 2012. Disponível em: $<$ http://www.scielo.br/scielo.php?script=sci_arttext\&pid=S010320032012000200009\& lng=pt\&nrm=iso>. Acesso em: 13 jan. 2018.

HALL, R. J.; FERREIRA, A. M. S.; AZEVEDO, A. P.; CARNIEL, C.; BACARJI, A. G.; BRYK, G. R. Gestão de custo das empresas rurais produtoras de grãos. In: Congresso UFSC Controladoria e Finanças \& Iniciação Científica em Contabilidade, $2^{\circ}, 2008$, Florianópolis-SC. Anais... Florianópolis-SC: UFSC, 2008. p. 1-12.

HOFER, E.; PACHECO, V.; SOUZA, A.; PROTIL, R. M. A relevância do controle contábil para o desenvolvimento do agronegócio em pequenas e médias propriedades rurais. Revista Contabilidade e Controladoria, v. 3, n. 1, p. 27-42, 2011.

INSTITUTO BRASILEIRO DE GEOGRAFIA E ESTATÍSTICA (IBGE). Indicadores IBGE: contas nacionais trimestrais indicadores de volume e valores correntes. Disponível em: <ftp://ftp.ibge.gov.br/Contas_Nacionais/Contas_Nacionais_Trimestrais/Fasciculo_Ind icadores_IBGE/pib-vol-val_201603caderno.pdf>. Acesso em: $01 \mathrm{dez} .2016$.

KRUGER, S. D.; GLUSTAK, E. F.; MAZZIONI, S.; ZANIN, A. A contabilidade como instrumento de gestão dos estabelecimentos rurais. Reunir - Revista de Administração, Ciências Contábeis e Sustentabilidade, v. 4, n. 2, p. 134-153, 2014.

LAKATOS, E. M.; MARCONI, M. A. Fundamentos de Metodologia Científica. 5. ed. São Paulo: Atlas, 2003.

MARION, J. C. Contabilidade Rural. 13. ed. São Paulo: Atlas, 2012. 
OLIVEIRA, E. C.; SOUZA, J. R. P.; FONSECA, E. P.; DIAS, F. M. V.; OLIVEIRA, D. L. Projeto Campo Fácil - UEL: Assistência Técnica e Difusão de Tecnologia aos Agricultores Familiares do Município de Londrina - PR. Extensão Rural, Santa Maria v. 24, n. 1, jan./mar. 2017, p. 120-129, 2017.

ONU. ONU lança ano internacional da agricultura familiar como indicador para redução da fome e da pobreza. 2013. Disponível em: $<$ http://www.un.org/apps/news/story.asp?NewsID=46566\#.VjNzlfmrTIU>. Acesso em: 25 Ago. 2015.

PICOLOTTO, E. L. Os Atores da Construção da Categoria Agricultura Familiar no Brasil. Revista de Economia e Sociologia Rural, Brasília, v. 52, supl. 1, p. 6384, 2014. Disponível

em:

<http://www.scielo.br/scielo.php?script=sci_arttext\&pid=S0103-

$20032014000600004 \&$ Ing=pt\&nrm=iso $>$. Acesso em: 13 jan. 2018.

PORTAL BRASIL. Agricultura familiar produz $70 \%$ dos alimentos consumidos por brasileiro. 2015. Disponível em: <http://www.brasil.gov.br/economia-eemprego/2015/07/agricultura-familiar-produz-70-dos-alimentos-consumidos-porbrasileiro>. Acesso em: 15 dez. 2015.

PORTAL PLANALTO. Responsável por $23 \%$ do PIB, plano safra impulsiona agropecuária. $2015 . \quad$ Disponível em: <http://www2.planalto.gov.br/noticias/2015/06/responsavel-por-23-do-pib-planosafra-impulsiona-agropecuaria>. Acesso em: 10 dez. 2015.

RAMPAZZO, L. Metodologia científica: para alunos dos cursos de graduação e pós-graduação. São Paulo: Loyola, 2002.

SANTOS, C. C. M.; CALLADO A. A. C. Gestão de custos nas empresas do setor avícola. In: Congresso Brasileiro de Custos, VII, 2000, Recife-PE. Anais... RecifePE: ABCustos, 2000.

SANTOS, J.; MARION, J. C.; SEGATTI, S. Administração de custos na agropecuária. 3. ed. São Paulo: Atlas, 2008.

SANTOS, I. A.; SIEBER, S. S.; FALCON, D. R. Piscicultura de Base Familiar como Estratégia para o Desenvolvimento Rural: Experiências no Estado de Pernambuco. Extensão Rural, Santa Maria, v. 21, n. 1, jan./mar., 2014. Disponível em: https://periodicos.ufsm.br/extensaorural/article/view/8620.

WALKER S. Drought, resettlement and accounting. Critical Perspectives on Accounting, v. 25, n. 7, p. 604-619, 2014.

YE, J.; PAN, L. Concepts and realities of family farming: in Asia and the Pacific. Working paper number 139. Published by the Food and Agriculture Organization of the United Nations and the International Policy Centre for Inclusive Growth of the United Nations Development Programme. April, 2016. Disponível em: <http://www.fao.org/publications/card/en/c/12460b63-b241-451c-8e6d-

47aff1403a80/>. Acesso em: 2 dez. 2016. 
ZANIN, A.; OENNING, V.; TRES, N.; KRUGER, S. D.; GUBIANI, C.; Gestão das Propriedades Rurais do Oeste de Santa Catarina: As Fragilidades da Estrutura Organizacional e a Necessidade do Uso de Controles Contábeis. Revista Catarinense da Ciência Contábil, v. 13, n. 40, p. 09-19, 2014. 